Original Article

\title{
Severity of Stress in Nurses Everyday Life in Karachi, Pakistan
}

\author{
Badil, Hakim Shah, Syed Arif Ali, Muhammad Arsalan Siddiqui
}

ABSTRACT

INTRODUCTION: Stress has been recognized as serious health problem among nurses. It declines the quality and standard of living with a great deterrence in health of its victims.

OBJECTIVES: To determine prevalence, severity and various stressors related to nurses everyday life.

METHODS: Hospital based analytical cross-sectional study was conducted from January 2015 to December 2015 in two tertiary care teaching hospitals of Karachi. The study was carried out on 265 registered nurses, having valid license by Pakistan Nursing Council. The subjects were approached by convenient nonprobability method. After taking written consent, semi-structured and pre-tested occupational stress questionnaire was used to obtain the data about various stressors related directly to nurse's everyday life. Significant level was considered at a $p$ value of 0.05 .

RESULTS: The study results revealed that majority of studied nurses $160(60.4 \%)$ were female and 148 $(55.8 \%)$ were married. $201(75.8 \%)$ had completed the diploma in nursing while $62(23.4 \%)$ had graduated their Post RN BSN. Out of total sample, $26(9.8 \%)$ nurses were working as a head nurse while $239(90 \%)$ as staff nurse. The study reveals through the participants' data that everyday life stress falls into three dimensions with their varying percentages as mild stress was found in $25.3 \%$, moderate in $39.6 \%$ and severe stress in $35.1 \%$ of the participants

CONCLUSION: The study result concluded that majority of nurses irrespective of their demographic characteristic have moderate or severe everyday life stress which may put negative effects on their both personal and professional responsibilities.

KEY WORDS: Stress, Nurses, Tertiary Care Hospitals, Pakistan.

This article may be cited as: Badil, Shah H, Ali SA, Siddiqui MA. Severity of Stress in Nurses Everyday Life in Karachi, Pakistan. J Liaquat Uni Med Health Sci. 2017;16(01):62-7. doi: 10.22442/jlumhs.171610508

\section{INTRODUCTION}

These days one of most discussed burning issue in health care environment of human life is spreading stress, it also causes imbalance in human psychology and physiological phenomenon ${ }^{1,17}$ Stress, further, declines the quality and standard of living with a great deterrence in health of its victims ${ }^{2}$.

Stress may lead to hypertension, cardiac problems, frustration and spoils the joy of life of nurses ${ }^{3}$. Moreover, stress becomes the source of psychological problems including sadness, depression, pessimism, negative attitude, lack of self-esteem and short temper ${ }^{4-6}$. It is revealed that environmental factors like excessive noise, pollution, time pressure and long standing hours are responsible for causing stress among nurses ${ }^{7}$. Financial difficulties, conflict with adult relatives or within the immediate family, unemployment of close relative, fear of joblessness are stressors which are particularly pertaining to a nurse's personal life ${ }^{5}$.

It has been confirmed by current research that quality of work and better outcomes has also been negatively influenced by stress. Thus, serious problems have occurred as a result of workplace stress, including high employee's turnover, absenteeism and accidents $^{8,16,18}$. Furthermore, it is affirmed that job performance decreases in stressful situations and there has been a significant relationship documented between job stress and job performance ${ }^{9,10}$ Stressed nurses fail to comply with the punctuality from the job and always feel lethargic, wishing to run away from the work as soon as possible ${ }^{11}$.

Stress has dire consequences like medical errors, noncompliance and negligence among nurses which may risk the patients' life and status ${ }^{12}$. Stressed workers seem to be less productive and ground organizational inefficiency ${ }^{9,19}$. Human being often faces stressful events in daily life as a consequence stress may intervene in the harmony of their life. Nurses are the backbone of healthcare and they are responsible for the proper care of the patients ${ }^{2}$. There is paucity of research on stress related to nurses' everyday life. The main objective of this study was to determine prevalence, severity and various stressors related to nurses' everyday life.

\section{METHODS}

The study design was the analytical cross-sectional 
study. This study was conducted at Civil Hospital and Dow University Hospitals in Karachi. Both hospitals are tertiary care public sector hospitals. The study duration was one year from January 2015 to December 2015. Male and female nurses having two years of work experience with full time job and valid license from Pakistan Nursing Council were included in the study. Nurses did not consent were excluded from the study. The participants were approached by convenient non-probability method. Open Epi 3.03 online version was used to calculate the sample size. Sample size calculated was $265(\mathrm{n}=265)$ subjects.

\section{Ethical Consideration}

Ethical permission was obtained from Institutional Review Board of Dow University of Health Sciences, Karachi. Permission was also taken from the Medical superintendent of Civil Hospital and Dow University of Health Sciences, Karachi to conduct the study proceedings.

A written informed consent was obtained from all subjects. The purpose of the study was explicitly explained to the participants. Privacy and confidentiality were assured. Code numbers were used for each questionnaire rather than name.

\section{Data Collection Instrument}

Data was collected by semi-structured stress questionnaire, about various stressors related to nurses' everyday life. A validated "Stress questionnaire" developed by Bhatia $\mathrm{N}^{3}$ was adopted after modification.

\section{Pilot study}

Pilot study was conducted on $10 \%$ of total sample size. The subjects included in pilot study were excluded from the original study. The study was piloted at Dow University Hospital and Civil Hospital Karachi. A minor vagueness on some questions was noticed and rectified.

The reliability of the questionnaire was checked by Chronbech's Alpha test. The result of this test showed that the questionnaire is $91.4 \%$ is reliable.

\section{Scoring of scale}

The degree and quantification of stress in the nurse's daily life was assessed by this questionnaire. The questionnaire comprises 12 possible sources of stress in daily life and 1-7 scores were displayed to be a source of stress from the lowest to highest degree. On the basis of these scores stress in everyday life of a nurse is classified as: no stress: 12 score, mild stress: 13 to 25 score, moderate stress: 26 to 40 score and severe stress: 41 to 84 score

\section{Statistical Analysis}

Data was entered and analyzed in SPSS version 21.0. Data was presented in Mean \pm SD for all quantitative variables while shown in frequency and percentages for all qualitative variables. Chi-squire test was used for comparison of the difference between gender, age, marital status, shift duty and workload with the outcome variable. Significance level was deliberated at a $p$-value of 0.05 .

\section{RESULTS}

Out of the total 265 nurses who participated in the study, $125(47.2 \%)$ nurses were between 25 to 30 years of age group. Out of total, majority $(n=160$, $60.4 \%$ ) were female and $148(55.8 \%)$ were married. Out of total $201(75.8 \%)$ majority of nurses were diploma qualified.

\section{TABLE I: DEMOGRAPHIC INFORMATION OF STUDY PARTICIPANTS}

\begin{tabular}{|c|c|c|}
\hline Information & $\mathbf{n}$ & $\%$ \\
\hline \multicolumn{3}{|c|}{ Age (Years) } \\
\hline $25-30$ & 125 & 47.2 \\
\hline $31-35$ & 42 & 15.8 \\
\hline $36-40$ & 46 & 17.4 \\
\hline $41 \&$ above & 52 & 19.6 \\
\hline \multicolumn{3}{|c|}{ Gender } \\
\hline Male & 105 & 39.6 \\
\hline Female & 160 & 60.4 \\
\hline \multicolumn{3}{|c|}{ Marital status } \\
\hline Single & 114 & 43.0 \\
\hline Married & 148 & 55.8 \\
\hline Widow & 3 & 1.1 \\
\hline \multicolumn{3}{|c|}{ Qualification } \\
\hline Diploma in nursing & 201 & 75.8 \\
\hline BSN post RN & 62 & 23.4 \\
\hline MSN & 2 & 0.8 \\
\hline
\end{tabular}

In Table II presents the stressors of everyday life stress in nurses. Stressors in nurses' everyday life are such as not having enough time for family, children and others, being at a risk of physical illness, suffering from mental and financial problem, dissatisfaction with working situation, being unable to fulfill family responsibilities and personal relationship, not finding secured in terms of employment status, they perceived that worrying about all or most of these issues compromised their efficiency at their workplace.

One-third $34.3 \%$ of nurses had enough time for their family and friends but rest $(65.7 \%)$ ensured the stress in variance, $20(7.5 \%)$ felt sever stress due to being at risk of physical illness, only $110(41.5 \%)$ felt that they may not suffer from mental problems which is a 
considerable minority of no stress, $17(6.4 \%)$ of nurses have high level of stress for financial problem. Only $15(5.7 \%)$ nurses were not happy with their working situation, 17(6.4) were felt that their employment status (position at work) is not up to standard, 22 $(8.3 \%)$ being unable to take care of their children and $24(9.1 \%)$ in others case timely. $26(9.8 \%)$ nurses felt unable to fulfill family responsibilities, $27(10.2)$ had poor personal relationship, $33(12.5 \%)$ nurses felt that they are not secure at work place.

Figure I presents the percentage of various sources of stress in nurses everyday life. The figure shows that $25.28 \%$ nurses had mild stress, $35.09 \%$ seemed to suffer from severe stress level yet the largest percentage $39.62 \%$ nurses fell into moderate stress. The prevalence of stress in nurse's everyday life was $100 \%$. No nurse's were found stress free.
Out of the total 256 nurses who participated in the study, 58(46.4\%) nurses were diagnosed with severe everyday life stress in 25-30 year of age group, whereas $67(38.95 \%)$ nurses had mild / moderate everyday life stress in that age group $(p=<0.001)$.

No statistically significant difference was found in everyday life stress of nurses by gender and their qualification. In terms of marital status, severe everyday life stress was reported around 51 (43.6\%) in unmarried nurses which is surprisingly higher than their married counterparts who were $42(28.4 \%)$ as sufferers at the time of study.

The percentage distribution of everyday life stress was found almost similar among staff and head nurses with $35.6 \%$ staff nurses and $30.8 \%$ head nurses had severe everyday life stress that is statistically insignificant, similar case with the distance from the

TABLE II:

PERCENTAGE DISTRIBUTION OF VARIOUS SOURCES OF STRESS IN NURSES' EVERYDAY LIFE

\begin{tabular}{|c|c|c|c|c|c|c|c|}
\hline Sources & $\begin{array}{c}\text { No } \\
\text { stress }=1\end{array}$ & 2 & 3 & 4 & 5 & 6 & $\begin{array}{c}\text { High } \\
\text { stress }=7\end{array}$ \\
\hline Frequency (\%) & $\mathrm{n}(\%)$ & $\mathrm{n}(\%)$ & $\mathrm{n}(\%)$ & $\mathrm{n}(\%)$ & $\mathrm{n}(\%)$ & $\mathrm{n}(\%)$ & $\mathrm{n}(\%)$ \\
\hline $\begin{array}{l}\text { Do not have enough time for your family/ } \\
\text { friends }\end{array}$ & $\begin{array}{c}91 \\
(34.3)\end{array}$ & $\begin{array}{c}31 \\
(11.7)\end{array}$ & $\begin{array}{c}41 \\
(15.5)\end{array}$ & $\begin{array}{c}34 \\
(12.8)\end{array}$ & $\begin{array}{c}32 \\
(12.1)\end{array}$ & $\begin{array}{c}22 \\
(8.3)\end{array}$ & $\begin{array}{c}14 \\
(5.3)\end{array}$ \\
\hline You feel that you are at risk of physical illness & $\begin{array}{c}46 \\
(17.4)\end{array}$ & $\begin{array}{c}95 \\
(35.8)\end{array}$ & $\begin{array}{c}39 \\
(14.7)\end{array}$ & $\begin{array}{c}15 \\
(5.7)\end{array}$ & $\begin{array}{c}26 \\
(9.8)\end{array}$ & $\begin{array}{l}24 \\
(9.1)\end{array}$ & $\begin{array}{c}20 \\
(7.5)\end{array}$ \\
\hline $\begin{array}{l}\text { You feel that you may suffering from mental } \\
\text { problems }\end{array}$ & $\begin{array}{c}110 \\
(41.5)\end{array}$ & $\begin{array}{c}40 \\
(15.1)\end{array}$ & $\begin{array}{c}44 \\
(16.6)\end{array}$ & $\begin{array}{l}24 \\
(9.1)\end{array}$ & $\begin{array}{c}19 \\
(7.2)\end{array}$ & $\begin{array}{c}18 \\
(6.8)\end{array}$ & $\begin{array}{c}10 \\
(3.8)\end{array}$ \\
\hline You often have financial problems & $\begin{array}{c}83 \\
(31.3)\end{array}$ & $\begin{array}{c}40 \\
(15.1)\end{array}$ & $\begin{array}{c}42 \\
(15.8)\end{array}$ & $\begin{array}{c}36 \\
(13.6)\end{array}$ & $\begin{array}{l}26 \\
(9.8)\end{array}$ & $\begin{array}{c}21 \\
(7.9)\end{array}$ & $\begin{array}{c}17 \\
(6.4)\end{array}$ \\
\hline You are not happy with your working situation & $\begin{array}{c}71 \\
(26.8) \\
\end{array}$ & $\begin{array}{c}62 \\
(23.4) \\
\end{array}$ & $\begin{array}{c}44 \\
(16.6)\end{array}$ & $\begin{array}{c}32 \\
(12.1) \\
\end{array}$ & $\begin{array}{c}25 \\
(9.4) \\
\end{array}$ & $\begin{array}{c}16 \\
(6.0)\end{array}$ & $\begin{array}{c}15 \\
(5.7)\end{array}$ \\
\hline $\begin{array}{l}\text { You feel that your employment status } \\
\text { (position at work) is not up to mark }\end{array}$ & $\begin{array}{c}70 \\
(26.4)\end{array}$ & $\begin{array}{c}33 \\
(12.5)\end{array}$ & $\begin{array}{c}40 \\
(15.1)\end{array}$ & $\begin{array}{c}40 \\
(15.1)\end{array}$ & $\begin{array}{c}27 \\
(10.2)\end{array}$ & $\begin{array}{c}38 \\
(14.3)\end{array}$ & $\begin{array}{c}17 \\
(6.4)\end{array}$ \\
\hline $\begin{array}{l}\text { You are unable to give required time to take } \\
\text { care of you children }\end{array}$ & $\begin{array}{c}88 \\
(33.2)\end{array}$ & $\begin{array}{c}45 \\
(17.0)\end{array}$ & $\begin{array}{c}27 \\
(10.2)\end{array}$ & $\begin{array}{c}42 \\
(15.8)\end{array}$ & $\begin{array}{c}22 \\
(8.3)\end{array}$ & $\begin{array}{c}19 \\
(7.2)\end{array}$ & $\begin{array}{c}22 \\
(8.3)\end{array}$ \\
\hline $\begin{array}{l}\text { You are unable to give required time to take } \\
\text { care of others }\end{array}$ & $\begin{array}{c}50 \\
(18.9)\end{array}$ & $\begin{array}{c}37 \\
(14.0)\end{array}$ & $\begin{array}{c}57 \\
(21.5)\end{array}$ & $\begin{array}{c}45 \\
(17.0)\end{array}$ & $\begin{array}{c}25 \\
(9.4)\end{array}$ & $\begin{array}{c}27 \\
(10.2)\end{array}$ & $\begin{array}{c}24 \\
(9.1)\end{array}$ \\
\hline $\begin{array}{l}\text { You are unable to fulfill your family } \\
\text { responsibilities }\end{array}$ & $\begin{array}{c}73 \\
(27.5)\end{array}$ & $\begin{array}{c}46 \\
(17.4)\end{array}$ & $\begin{array}{c}48 \\
(18.1)\end{array}$ & $\begin{array}{l}24 \\
(9.1)\end{array}$ & $\begin{array}{c}22 \\
(8.3)\end{array}$ & $\begin{array}{l}26 \\
(9.8)\end{array}$ & $\begin{array}{l}26 \\
(9.8)\end{array}$ \\
\hline You have poor personal relationship & $\begin{array}{c}72 \\
(27.2)\end{array}$ & $\begin{array}{c}64 \\
(24.2)\end{array}$ & $\begin{array}{c}24 \\
(9.1)\end{array}$ & $\begin{array}{c}36 \\
(13.6)\end{array}$ & $\begin{array}{c}18 \\
(6.8)\end{array}$ & $\begin{array}{l}24 \\
(9.1)\end{array}$ & $\begin{array}{c}27 \\
(10.2)\end{array}$ \\
\hline $\begin{array}{l}\text { You are being discriminated in very day } \\
\text { situation }\end{array}$ & $\begin{array}{c}52 \\
(19.6)\end{array}$ & $\begin{array}{c}44 \\
(16.6)\end{array}$ & $\begin{array}{c}67 \\
(25.3)\end{array}$ & $\begin{array}{c}45 \\
(17.0)\end{array}$ & $\begin{array}{c}16 \\
(6.0)\end{array}$ & $\begin{array}{c}28 \\
(10.6)\end{array}$ & $\begin{array}{c}13 \\
(4.9)\end{array}$ \\
\hline You do not find you are secure & $\begin{array}{c}62 \\
(23.4)\end{array}$ & $\begin{array}{c}46 \\
(17.4)\end{array}$ & $\begin{array}{c}46 \\
(17.4)\end{array}$ & $\begin{array}{c}29 \\
(10.9)\end{array}$ & $\begin{array}{l}24 \\
(9.1)\end{array}$ & $\begin{array}{l}25 \\
(9.4)\end{array}$ & $\begin{array}{c}33 \\
(12.5)\end{array}$ \\
\hline
\end{tabular}


workplace in relation to everyday life stress. Working hours has noticeable impact on routine life stress level. Among study participants higher percentage $(49.3 \%)$ of nurses working in evening shifts show severe everyday stress that is statistically significant with $p$ value of 0.013 . It is evident from data that work load had no statistically significant effect on everyday stress levels. Employees working on contract basis had higher routine life stress levels with $46.8 \%$ ) individuals complaining about it as compared to regular employees. Hence it is statistically significant $p$ value 0.064. Among nurses included in study participants who have less than 10 years' experience had higher everyday stress levels, 47\% than participants with above 10 years of experience. This is statistically significant $p$ value $<.001$. Data shows that income has statistically significant ( $p$ value .011) impact on everyday life stress as $47.5 \%$ nurses with income 25,000 - 34000 had fair level of severe routine life stress.
FIGURE I: PERCENTAGE OF VARIOUS SOURCES OF STRESS IN NURSES EVERYDAY LIFE

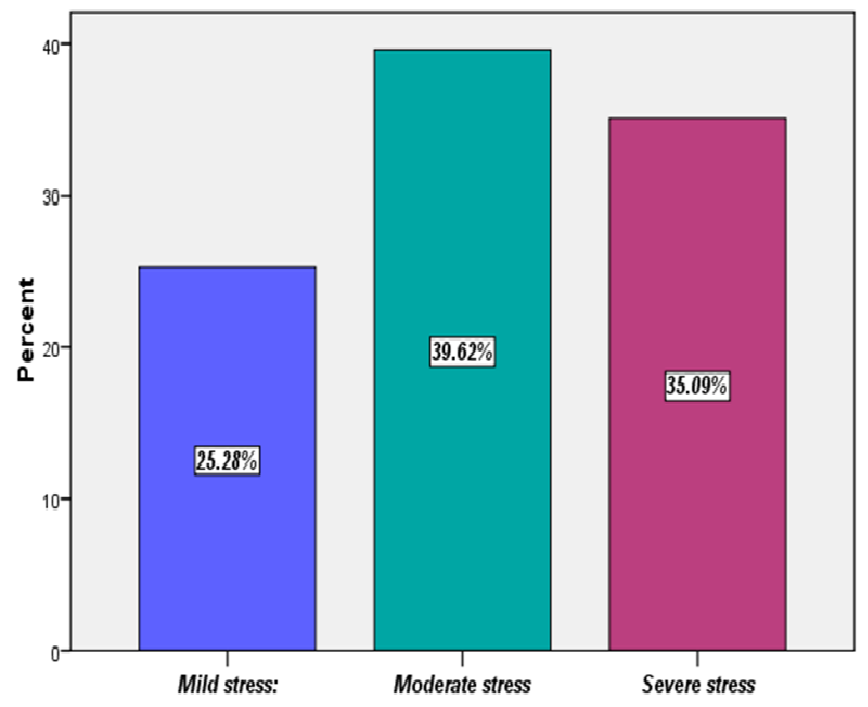

TABLE III: ASSOCIATION OF DEMOGRAPHIC INFORMATION AND STRESS IN NURSES' EVERYDAY LIFE

\begin{tabular}{|c|c|c|c|c|c|c|c|c|}
\hline \multirow{2}{*}{$\begin{array}{c}\text { Information } \\
\text { Frequency (\%) }\end{array}$} & \multicolumn{2}{|c|}{ Mild stress } & \multicolumn{2}{|c|}{ Moderate stress } & \multicolumn{2}{|c|}{ Severe stress } & \multirow{2}{*}{$\begin{array}{c}\text { Pearson } \\
\text { Chi-Square }\end{array}$} & \multirow{2}{*}{ P-value } \\
\hline & $\mathrm{n}$ & $\%$ & $\mathrm{n}$ & $\%$ & $\mathrm{n}$ & $\%$ & & \\
\hline \multicolumn{7}{|l|}{ Age (Years) } & 24.46 & $<0.001$ \\
\hline $25-30$ & 20 & $16.0 \%$ & 47 & $37.6 \%$ & 58 & $46.4 \%$ & & \\
\hline $31-35$ & 7 & $16.7 \%$ & 16 & $38.1 \%$ & 19 & $45.2 \%$ & & \\
\hline $36-40$ & 23 & $50.0 \%$ & 14 & $30.4 \%$ & 9 & $19.6 \%$ & & \\
\hline $41 \&$ above & 17 & $32.7 \%$ & 28 & $53.8 \%$ & 7 & $13.5 \%$ & & \\
\hline \multicolumn{7}{|l|}{ Gender } & 1.193 & .275 \\
\hline Male & 21 & $20.0 \%$ & 43 & $41.0 \%$ & 41 & $39.0 \%$ & & \\
\hline Female & 46 & $28.8 \%$ & 62 & $38.8 \%$ & 52 & $32.5 \%$ & & \\
\hline \multicolumn{7}{|l|}{ Marital status } & 6.638 & 0.01 \\
\hline Single / Widow & 23 & $19.7 \%$ & 43 & $36.8 \%$ & 51 & $43.6 \%$ & & \\
\hline Married & 44 & $29.7 \%$ & 62 & $41.9 \%$ & 42 & $28.4 \%$ & & \\
\hline \multicolumn{7}{|l|}{ Qualification } & 0.583 & 0.445 \\
\hline Diploma in nursing & 57 & $28.4 \%$ & 76 & $37.8 \%$ & 68 & $33.8 \%$ & & \\
\hline BSN post RN/ MSN & 10 & $15.6 \%$ & 29 & $45.3 \%$ & 25 & $39.1 \%$ & & \\
\hline
\end{tabular}

\section{DISCUSSION}

It has been revealed by various research studies that most nurses experience moderate to severe stress in their everyday life. Nurses are supposed to be the backbone of health care setup, they render the proper care channel to the patients. However, family conflicts, safety and security, financial problems and discrimination are the factors affecting their personal and social life. Therefore, it often leads them to suffer from undue stress which negatively influences their potential that's 
why patients' care is highly compromised. Surprisingly, there is a limited research on various sources of stress or stressors on nurses' everyday life and in the developing countries ${ }^{13}$.

The age group is also a major factor, in a study conducted in India, ${ }^{3}$ the mean age of nurses' participants was 32.5 years (range $22-41$ years). In other study ${ }^{14}$ the participants were between 20-50 years of age. Further, in this study results were also almost identical to it as the age of nursing participants in this study was 25 to 50 years. According to this study severe stress increased as age of the participants rose, however it was not statistically significant $(P=0.06)$.

As far as gender and marital distribution is concerned, in a study ${ }^{13}$ majority $76.7 \%$ were females and only $23.3 \%$ were males and majority of the participants were married $(63.3 \%)$. Similarly in another study ${ }^{1}$ majority $(80.4 \%)$ participant nurses were married. In this study participants were also similar to these as $60.4 \%$ of participants were females and $39.6 \%$ were males and $55.8 \%$ of them were married. However gender and marital status was not found any significance ( $p=0.98 \& p=0.79$ respectively.)

According to a study $387.45 \%$ of the nurses found stress in their everyday life, in the same study only $1.1 \%$ claimed mild stress, $52.9 \%$ moderate stress and $34.5 \%$ as severe stress. In another study ${ }^{15} 34.6 \%$ of the participants were satisfied with their interpersonal relationship and everyday life stress was found similar to above studies as mild stress was found in $25.3 \%$, moderate in $39.6 \%$ and severe stress in $35.1 \%$ of the participants. In this study $82.4 \%$ nurses felt that they are at the risk of physical illness, it was considered the most stressful. Similarly in another study ${ }^{3}$ majority $60.9 \%$ reported about risk of physical illness. In this study $41.5 \%$ nurses felt that they were not suffering from mental problems and it was considered as the least stressful. Similarly in another study ${ }^{3} 56.3 \%$ nurses reported not having mental problems.

\section{LIMITATIONS}

This study was carried out in two public sector tertiary care hospitals of Karachi so, results cannot be generalized for all population. The participants in the study belonged to urban setting of hospitals. Thus; the results could not be applied to nurses of the hospitals in rural area settings. The study was conducted in public sector hospitals, so it can figure level of stress out among nurses working in private sector.

\section{STRENGTH OF THE STUDY}

The study was conducted first time in Pakistani setting and it is providing baseline data about occupational stress among nurses of Karachi. This research also provides the ground to explore the basis to initiate researches for causes and intervention in occupational stress.

\section{CONCLUSION}

Majority of nurses irrespective of their demographic characteristic have moderate to severe everyday life stress which may put negative effect on their professional, personal, and social responsibilities. It is therefore recommended that their job stress should be reduced by adopting proper management and better service atmosphere.

\section{RECOMMENDATIONS}

It is, through the results of this study, recommended that Government incorporate stress reduction program in national health policy. Stress reduction seminars to be conducted, vacations to be provided for entertainment on yearly basis. Large scale follow up study is suggested to be conducted that will determine factors causing stress in nurses' everyday life.

\section{REFERENCES}

1. Arbabisarjou $A$, Ajdari $Z$, Omeidi $K H$, Jalalinejad $R$. The relationship between Job stress and performance among the hospitals Nurses. World Sci J. 2013; 1:181-8.

2. Long CS, Kowang TO, Ping TA, Muthuveloo R. Investigation on the impact of job stressors on nurses in Malaysia. Asian Soc Sci. 2014;10(4):6777.

3. Bhatia N, Kishore J, Anand T, Jiloha RC. Occupational stress amongst nurses from two tertiary care hospitals in Delhi. Australas Med J. 2010;3(11):731-8.

4. McVicar A. Workplace stress in nursing: a literature review. J Adv Nurs. 2003;44(6):633-42.

5. McGrath A, Reid N, Boore J. Occupational stress in nursing. International Journal of Nursing Studies (1989), 26, 359-368. Int J Nurs Stud. 2003;40(5):555-65.

6. Milutinović D, Golubović B, Brkić N, Prokeš B. Professional stress and health among critical care nurses in Serbia. Arch Hig Rada Toksikol. 2012;63(2):171-80.

7. Kane PP. Stress causing psychosomatic illness among nurses. Indian J Occup Environ Med. 2009 Jan 1; 13(1):28-32.

8. AbuAIRub RF. Job stress, job performance, and social support among hospital nurses. J Nurs Scholarsh. 2004;36(1):73-8.

9. Mark G, Smith AP. Occupational stress, job characteristics, coping, and the mental health of nurses. Br J Health Psychol. 2012;17(3):505-21.

10. CDC-NIOSH. Stress at work. Available from: http://www.cdc.gov/niosh/docs/99-101 
11. Al-khasawneh AL, Futa S. The Relationship between Job Stress and Nurses Performance in the Jordanian Hospitals: A Case Study in King Abdullah the Founder Hospital. Asian J Bus Manag. 2013;5(2):267-75.

12. Babu GR, Sathyanarayana TN, Ketharam A, Kar SB, Detels R, Perceived occupational stressors and the health software professionals in Bengaluru, India, The qualitative Report 2015;20 (3):314-35

13. Chant S, Jenkinson T, Randle J, Russell G. Communication skills: some problems in nursing education and practice. J Clin Nurs. 2002; 11 (1):12-21.

14. Eleni $M$, Fotini $A$, Maria $M$, et al. Research in occupational stress among nursing staff, a comparative study in Capital and Reginal hospitals, HJNS 2014;3(3):79-84.

15. Jaafarpour M, Khani A. Evaluation of the nurses' job satisfaction, and its association with their moral sensitivities and well-being. J Clin Diagn Res. 2012;6(10):1761-4.

16. Wu H, Chi TS, Chen L, Wang L, Jin YP. Occupational stress among hospital nurses: cross -sectional survey. J Adv Nurs. 2010; 66(3):627-34.

17. Wu S, Zhu W, Wang Z, Wang M, Lan Y. Relationship between burnout and occupational stress among nurses in China. J Adv Nurs. 2007; 59(3):233-9.

18. Nabirye RC, Brown KC, Pryor ER, Maples EH. Occupational stress, job satisfaction and job performance among hospital nurses in Kampala, Uganda. J Nurs Manag. 2011; 19(6):760-8

19. Yang MS, Pan SM, Yang MJ. Job strain and minor psychiatric morbidity among hospital nurses in southern Taiwan. Psychiatry Clin Neurosci. 2004; 58(6):636-41.

\begin{tabular}{|l|}
\hline AUTHOR AFFILIATION: \\
Badil (Corresponding Author) \\
Institute of Nursing \\
Dow University of Health Sciences \\
Karachi, Sindh-Pakistan. \\
Email: goilpatwani@yahoo.com \\
Hakim Shah \\
Institute of Nursing \\
Dow University of Health Sciences \\
Karachi, Sindh-Pakistan. \\
Syed Arif Ali \\
Research Department \\
Dow University of Health Sciences \\
Karachi, Sindh-Pakistan. \\
Muhammad Arsalan Siddiqui \\
Institute of Nursing \\
Dow University of Health Sciences \\
Karachi, Sindh-Pakistan.
\end{tabular}

